\title{
Influence of technogenic factors on the engineering and geological conditions of the gas plant territory in the Orenburg region
}

\author{
Nadezhda Korvet $^{1,{ }^{*}}$, Maria Zavodchikova ${ }^{2}$, and Marina Lazdovskaya ${ }^{1}$ \\ ${ }^{1}$ St. Petersburg State University, Saint-Petersburg, Russia \\ ${ }^{2}$ St. Petersburg State University of Architecture and Civil Engineering, Saint-Petersburg, Russia
}

\begin{abstract}
The engineering and geotechnical conditions of the site of the helium plant in the Orenburg region are characterized. The possibility of its technogenic pollution has been identified by the results of literary and stock sources, as well as by engineering and geological surveys. The reason for the formation of pollution sites is substantiated. This fact is confirmed by analyzes of assessing the composition of groundwater and the physicomechanical properties of loess soils that make up the upper part of the geological section. Groundwater is characterized by increased mineralization, which is mainly caused by the high content of sulfates, chlorides, magnesium and calcium. Also, there is an increased content of ammonia, the smell of gasoline. Studies of the soil properties showed that it almost lost subsidence properties, with the exception of isolated cases. The subsidence of individual soil samples taken from a depth of 13.0-20.0 $\mathrm{m}$ is inexplicable by natural causes due to the impossibility of steeping them, taking into account the hydrogeological conditions of the site. It indicates an irreversible effect of leaks of chemical reagents on the soil. The established engineering and geological features of soils and their behavior along the depth of the section are confirmed by test results presented in the form of tables and graphs. The presented information is of great practical and scientific importance for predicting changes in the characteristics of the geological environment during technogenic pollution at oil and gas facilities. The feasibility of amending regulatory documents for a detailed study of this problem in accordance with existing recommendations and scientific developments is proposed.
\end{abstract}

\section{Introduction}

The nature and patterns of man-made changes in the geological environment are one of the priority areas for the development of engineering geology in the 21 st century. [1,2]. In the concept of "geological environment", the central place is occupied by natural geological conditions, which determine the rationale for the construction and operation of structures in a particular territory. With respect to the goals of construction practice, they are considered as "engineering and geological conditions (EGC)" [3]. Among the main elements of EGC,

* Corresponding author: nnkorvet2010@yandex.ru 
the leading role is played by soils and groundwater, and the assessment of their change under the influence of technogenic pollution is quite important $[4,5,6,7]$. To a large extent, this problem is relevant in the territories of oil and gas production complexes, both in Russia and abroad [8,9, 10].

One of the objects of the gas industry in Russia, the operation of which has a deep technogenic impact on the environment, is the Orenburg gas field, which has been operating since February 1974, and the territory of the Orenburg region has been characterized as the most transformed in technogenic way, [11, 12, 13, 14, 15]. In 2006, on the site of one of the structural divisions of the Orenburg gas field - Helium plant, Neftegazgeodeziya LLC carried out engineering and geological surveys due to the need for its reconstruction [16]. An assessment of the state of groundwater in the area of the helium plant was also made by VolgoUralNIPIgaz LLC as part of environmental engineering surveys [17]. An analysis of the obtained materials and literary and stock sources for this facility revealed the possibility of technogenic pollution of the site, which had an impact on the characteristics of the physicomechanical properties of soils and the composition of groundwater. The results of the analysis are presented in this paper.

\section{Materials and methods}

The engineering and geological conditions of the territory of the Orenburg gas field are determined according to the engineering and geological zoning and by confining to the southeastern slope of Obshchiy Syrt within the Caspian syneclise [18].

Engineering and geological surveys carried out at the study site in 2006 included field work with sampling of soils and subsequent determination of the complex of their physical and mechanical properties, as well as sampling of water to assess its chemical composition. It should be noted that prior to the start of work, the materials of surveys carried out before the construction of the facility began in 1974 were not obtained in sufficient quantities, while the upbrows were located at a considerable distance from the wells drilled in 2006. Given the heterogeneity of the geological section, the previously obtained data could not fully reliably characterize the studied site. From the provided information it follows that the site is composed of Pliocene-Quaternary loesslike syrtic loams and clays to a depth of 10$15 \mathrm{~m}$, which are underlain by the heterogeneous mass of Permian deposits represented by clays, mudstones, sandstones and limestones. Syrtic deposits were characterized as subsidence soils with heterogeneous subsidence of type I-II [16, 19].

\section{Results and discussion}

One of the primary tasks of the survey was to clarify the geological structure of the site and hydrogeological conditions. The results of drilling 38 wells and processing the obtained data showed that the Upper Permian rocks $\left(\mathrm{P}_{2} \mathrm{t}\right)$ come to the surface in its southwestern part, represented by intercalation of clays, siltstones, mudstones and sandstones, with lenses of sand, with rare interlayers of limestone and marl. Their uncovered thickness is on average about $4.5 \mathrm{~m}$, and the maximum $-9.4 \mathrm{~m}$. In the rest of the site, they are almost everywhere covered by sediments of Pliocene-Quaternary age (ld $\mathrm{N}_{2}-\mathrm{Q}_{\text {II }}$ ) (maximum thickness - more than $30.5 \mathrm{~m}$ ), and in some areas - Paleogene-Quaternary eluvial-deluvial soils (ed P-Q) with a thickness of 3.3 up to $5.3 \mathrm{~m}$. Technogenic soils lie on the surface (Figure 1).

The groundwater of the first aquifer from the surface is confined to Perm rocks $\left(\mathrm{P}_{2} \mathrm{t}\right)$. Its feeding is carried out due to atmospheric precipitation infiltration in the areas where the bedrock emerges to the surface, water discharge occurs in the valleys of watercourses. 
Water-bearing rocks are unevenly fractured sandstones and siltstones alternating with clays. The depth of groundwater tapping is from $2.9 \mathrm{~m}$ to $17.5 \mathrm{~m}$. According to the occurrence conditions, the aquifer has a pressure-free character, the local pressure reaches $6.5 \mathrm{~m}$, averaging $3.4 \mathrm{~m}$. The aquifer system of Perm rocks is blocked everywhere by a layer of poorly permeable loams and clays of Quaternary age. Clay filtration coefficients range from 0.00004 to $0.001 \mathrm{~m} /$ day, loams from 0.0026 to $0.0082 \mathrm{~m} /$ day. Thin phreatimetric lenses of water saturated sand are exposed by individual wells in the thickness of clays and loams. When performing survey work on the territory of the plant, the emerging and steady-state level of groundwater was measured in all the wells that uncovered groundwater. Considering that the main pressure-phreatimetric groundwater aquifer for which observation hydrogeological wells are equipped is confined to the weathering zone of native Permian rocks. It lies at a depth of about $11 \mathrm{~m}$ and is blocked by the mass of lowpermeable loams. It does not adversely affect the foundations of buildings and structures. In particular, a seasonal rise in groundwater level does not lead to the steeping of foundations. This is also confirmed by monitoring observations of the Laboratory of VolgoUralNIPIgaz LLC, according to which, there was no flooding of the territory during the operation of the helium plant from 2003 to 2005 [17].

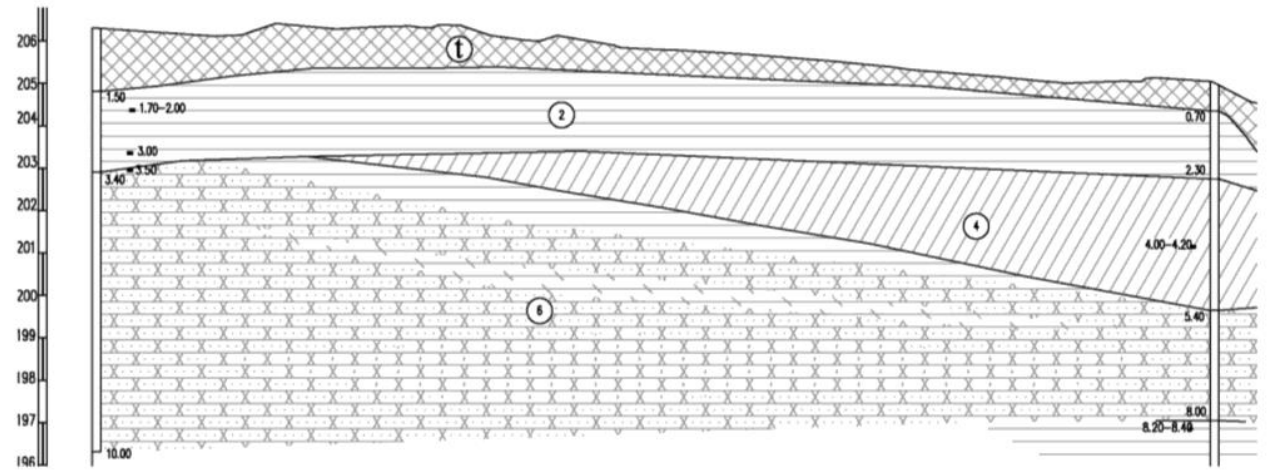

Fig. 1. Schematic geological and lithological section of the site (fragment). $t$ - technogenic soils, 2Pliocene-Quaternary sediments, 4- Paleogene-Quaternary sediments, 6 - mass of the Upper Permian rocks.

As indicated above, the territory is characterized by an unfavorable ecological and geological situation, which was revealed during the survey. When drilling in wells, the smell of kerosene, gasoline and chemicals was observed to a depth of $10.5 \mathrm{~m}$, in some areas up to $16 \mathrm{~m}$. Directly in the laboratory, when opening the monoliths, an unnatural color was observed in some samples due to the mosaic shape of the distribution of darker spots in the bulk of the soil. There was also the smell of the above mentioned substances, which indicated contamination of the soil with chemical reagents.

The possible formation of pollution sites probably occurred as a result of accidental leaks during transportation and storage of industrial waste containing oil products, methanol, hydrogen sulfide, and other various chemicals. It should also take into account the aggravation of the ecological and geological situation in the territory due to the accident at the Orenburg helium plant that occurred in 2003 due to the leakage of the propane-butane fraction from the gas pipeline and subsequent fire and explosions [20]. These factors contributed to the transformation of the EGC of the territory in question, primarily groundwater and soil.

Significant zones of pollution of natural waters were formed around the helium plant $[21,22,23]$. Analysis of the chemical composition of groundwater (according to 
Neftegazgeodeziya LLC) within the area under consideration showed that they have mainly sulfate or chloride-bicarbonate magnesium-sodium composition. Their mineralization varies from 0.5 to $8.8 \mathrm{~g} / \mathrm{l}$, its increase is mainly associated with a high content of sulfates, chlorides, magnesium and calcium. An increased (up to $0.8 \mathrm{mg} / \mathrm{l}$ ) ammonia content and the smell of gasoline were noted in water samples. These factors confirm the development of local foci of technogenic pollution and are caused by these reasons.

Also, there was a transformation of physical and mechanical properties of soils. The chemical elements contained in industrial effluents, participating in ion-exchange reactions when interacting with soils, contribute to a change in the parameters of the double electric layer, affecting the ion-electrostatic component of the wedging pressure between the particles and causing a change in the soil microstructure, and water resistance of bonds. To a large extent, this process determines, among others, such properties of dispersed soils as subsidence and swelling [24].

The studies of the physical and mechanical properties of soils, which were carried out in the laboratories of "NEFTEGAZGEODESIYA", "VNIIG" OJSC named after Vedeneev B.E. and the Department of Soil Science and Engineering Geology of St. Petersburg State University, including the authors of the paper, revealed their features (Corvette et al. 2016). For clay soils, particle size distribution, physical and mechanical properties were determined. Based on drilling data, sediment genesis, generalization of indicators of physical and mechanical properties of soils, the characteristics of which are described below, engineering and geological elements (EGE) were identified in the rock sequence. Pliocene-Quaternary subaerial syrtic sediments: EGE-1 - loam of solid and semi-solid consistency, non-subsiding; EGE-1a - loam of solid and semi-solid consistency, subsiding; EGE-2 - clay of solid and semi-solid consistency, non-subsiding; EGE-2a - clay of solid consistency, subsiding; EGE-3 - sand. Paleogene-Quaternary eluvial-deluvial sediments: EGE-4 - loam of solid and semi-solid consistency, rarely subsiding; EGE-5 - clay of solid and semi-solid consistency, rarely subsiding. The mass of the bedrock represented by an irregular alternation of weathered clay of varying degrees of solid consistency, mudstones, siltstones and sandstones, with thin layers of sand is highlighted in EGE-6. The average values of the characteristics of their properties are presented in Table 1, from which it follows that clay and loamy soils are characterized by a rather high density exceeding 2.00 $\mathrm{g} / \mathrm{cm}^{3}$, with the exception of soils EGE-1a and EGE-2a, for which the water saturation coefficient $\left(\mathrm{S}_{\mathrm{r}}\right)$ is $0.77 \ldots 0.78$; for other soils - 0.87...0.90-0.97. It should be noted that according to the survey in 1974, the density of Pliocene-Quaternary and PaleogeneQuaternary soils was $1.67 \ldots 1.69 \mathrm{~g} / \mathrm{cm}^{3}$ [19]. Table 1 .

Table 1. Average values of indicators of physical properties of soils.

\begin{tabular}{|c|c|c|c|c|c|c|}
\hline & $\mathrm{W}, \%$ & $\mathrm{I}_{\mathrm{p}}, \%$ & $\mathrm{I}$, u.f. & $\begin{array}{c}\rho \\
\mathrm{g} / \mathrm{cm}^{3}\end{array}$ & $\begin{array}{c}\rho_{\mathrm{d}}, \\
\mathrm{g} / \mathrm{cm}^{3}\end{array}$ & e, u.f. \\
\hline $\begin{array}{c}\text { EGE } \\
1\end{array}$ & 19.6 & 15.4 & -0.247 & 2.01 & 1.68 & 0.614 \\
\hline $\begin{array}{c}\text { EGE } \\
1 \mathrm{a}\end{array}$ & 19.7 & 15.8 & -0.237 & 1.92 & 1.60 & 0.699 \\
\hline $\begin{array}{c}\text { EGE } \\
2\end{array}$ & 20.8 & 18.9 & -0.158 & 2.03 & 1.68 & 0.620 \\
\hline $\begin{array}{c}\text { EGE } \\
2 \mathrm{a}\end{array}$ & 21.9 & 18.4 & -0.092 & 1.88 & 1.54 & 0.767 \\
\hline $\begin{array}{c}\text { EGE } \\
4\end{array}$ & 20.7 & 13.8 & -0.176 & 2.01 & 1.66 & 0.637 \\
\hline
\end{tabular}




\begin{tabular}{|c|c|c|c|c|c|c|}
\hline $\begin{array}{c}\text { EGE } \\
5\end{array}$ & 21.1 & 20.3 & -0.146 & 2.02 & 1.66 & 0.640 \\
\hline $\begin{array}{c}\text { EGE } \\
6\end{array}$ & 20.2 & 21.6 & $\begin{array}{c}- \\
0.231\end{array}$ & 2.10 & 1.74 & 0.566 \\
\hline
\end{tabular}

Table 2 shows the values of the indicators of the mechanical properties of soils (E is the deformation modulus at natural humidity, Ew is the deformation modulus at water saturation; A (adhesion) and $\varphi$ (angle of internal friction) - the numerator shows values at natural humidity, the denominator - at full water saturation).

Table 2. Average values of indicators of the mechanical properties of soils.

\begin{tabular}{|c|c|c|c|c|}
\hline & $\begin{array}{c}\mathrm{E} \\
\mathrm{MPa}\end{array}$ & $\begin{array}{c}\mathrm{E}_{\mathrm{w}} \\
\mathrm{MPa}\end{array}$ & $\begin{array}{c}\mathrm{A} \\
\mathrm{MPa}\end{array}$ & $\begin{array}{c}\varphi \\
\text { degrees }\end{array}$ \\
\hline $\begin{array}{c}\mathrm{EGE} \\
1\end{array}$ & 40.0 & 32.1 & $69 / 19$ & $46 / 18$ \\
\hline $\begin{array}{c}\mathrm{EGE} \\
1 \mathrm{a}\end{array}$ & 23.2 & 10.3 & $61 / 42$ & $17 / 12$ \\
\hline $\begin{array}{c}\mathrm{EGE} \\
2\end{array}$ & 50.2 & 37.4 & $98 / 96$ & $28 / 16$ \\
\hline $\begin{array}{c}\mathrm{EGE} \\
2 \mathrm{a}\end{array}$ & 30.2 & 12.9 & $128 / 108$ & $17 / 13$ \\
\hline $\begin{array}{c}\mathrm{EGE} \\
4\end{array}$ & 30.8 & 39.9 & $47 /-$ & $21 /-$ \\
\hline $\begin{array}{c}\mathrm{EGE} \\
5\end{array}$ & 55.6 & 36.7 & $116 /-$ & $19 /-$ \\
\hline
\end{tabular}

The main objectives of the survey included identifying the distribution of subsidence soils. In order to determine the tendency of soils to subsidence, 300 samples of the natural structure were tested in laboratory conditions using compression devices without the possibility of lateral expansion of the soil. The tests were performed using one of the following methods - "one curve" and "two curves". The subsidence of samples taken to a depth of $6 \mathrm{~m}$ was estimated by the method of two curves, deeper than $6 \mathrm{~m}$ - by the method of one curve, and in the case of soil macroporosity - by two curves. The research results showed that almost everywhere they do not have subsidence properties, and when soaked, their behavior varies significantly. Out of 38 wells, only five wells in soils at different depths revealed subsidence. For Pliocene-Quaternary soils, for only $4 \%$ of the samples, the relative subsidence strain $\left(\varepsilon_{s l}\right) \geq 0.01$ at normal pressure characterized them as subsidental. For samples taken from eluvial-deluvial sediments, only 3 samples were assigned to subsidence, the sampling depth of which was 3.8-4.0 m; 6.3-6.6 m; 21.3-21.6m. At the same time, soils have subsidence of type I and II (Figures 2 and 4). 


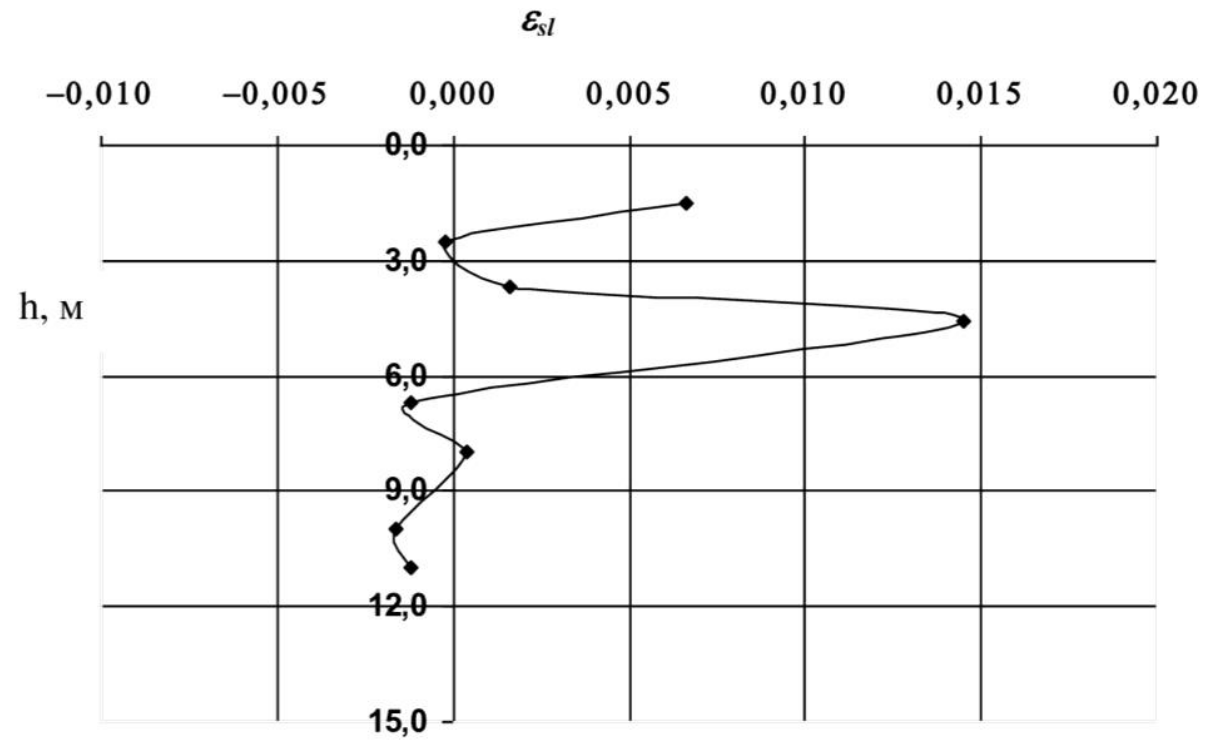

Fig. 2. Subsidence of type II. The average value of relative subsidence, u.f. - 0.0198; The thickness of the subsidence layer, $\mathrm{m}-3.1$; subsidence value, $\mathrm{cm}-6.1483$.

Some samples taken from the upper part of the section (to a depth of about $6 \mathrm{~m}$ ) showed the ability to swell, both without load and under load. In terms of the size of free swelling, they were characterized as weakly, medium, and strongly swelling.

In some areas, the soils showed subsidence properties at considerable depths. As an example, the results of determining the relative subsidence strain $\left(\varepsilon_{s l}\right)$ for one of the wells are shown (Figure 3). The indicators of their physical properties are shown in table 3.

Table 3. Physical properties of soils taken from different depths.

\begin{tabular}{|c|c|c|c|c|c|c|c|}
\hline Depth & $\begin{array}{l}\mathrm{W} \\
\%\end{array}$ & $\begin{array}{l}I_{p}, \\
\%\end{array}$ & $\begin{array}{l}I_{L}, \\
\text { u.f. }\end{array}$ & $\begin{array}{c}\rho \\
\mathrm{g} / \mathrm{cm}^{3}\end{array}$ & $\begin{array}{l}\rho d, \\
\mathrm{~g} / \mathrm{c} \\
\mathrm{m}^{3}\end{array}$ & $\begin{array}{c}e, \\
\text { u.f. }\end{array}$ & $S_{r}$ \\
\hline 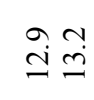 & 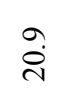 & $\stackrel{+}{ \pm}$ & $\begin{array}{l}0 \\
n \\
n \\
0\end{array}$ & $\stackrel{\infty}{-}$ & $\stackrel{n}{n}$ & $\frac{n}{2}$ & $\frac{n}{0}$ \\
\hline ָั & $\vec{a}$ & $\ddot{v}$ & ڤิ & $\stackrel{\infty}{\circledR}$ & $\stackrel{\circ}{+}$ & $\begin{array}{l}\hat{0} \\
\infty \\
0\end{array}$ & $\stackrel{m}{0}$ \\
\hline 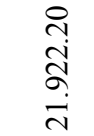 & $\stackrel{\circ}{\stackrel{\sim}{े}}$ & $\hat{\overbrace{}}$ & $\frac{\tilde{2}}{\stackrel{0}{0}}$ & $\hat{\alpha}$ & $\stackrel{t}{\mathbb{S}}$ & $\begin{array}{l}\hat{\infty} \\
0 \\
0\end{array}$ & $\begin{array}{l}\infty \\
0\end{array}$ \\
\hline
\end{tabular}


Over the entire depth of the section, soils do not have subsidence properties. At the same time, in separate sampling intervals, at depths given in Table 3 and indicated in section 1a and 2a (EGE-1a and EGE-2a), they are subsidental (Figure 4).

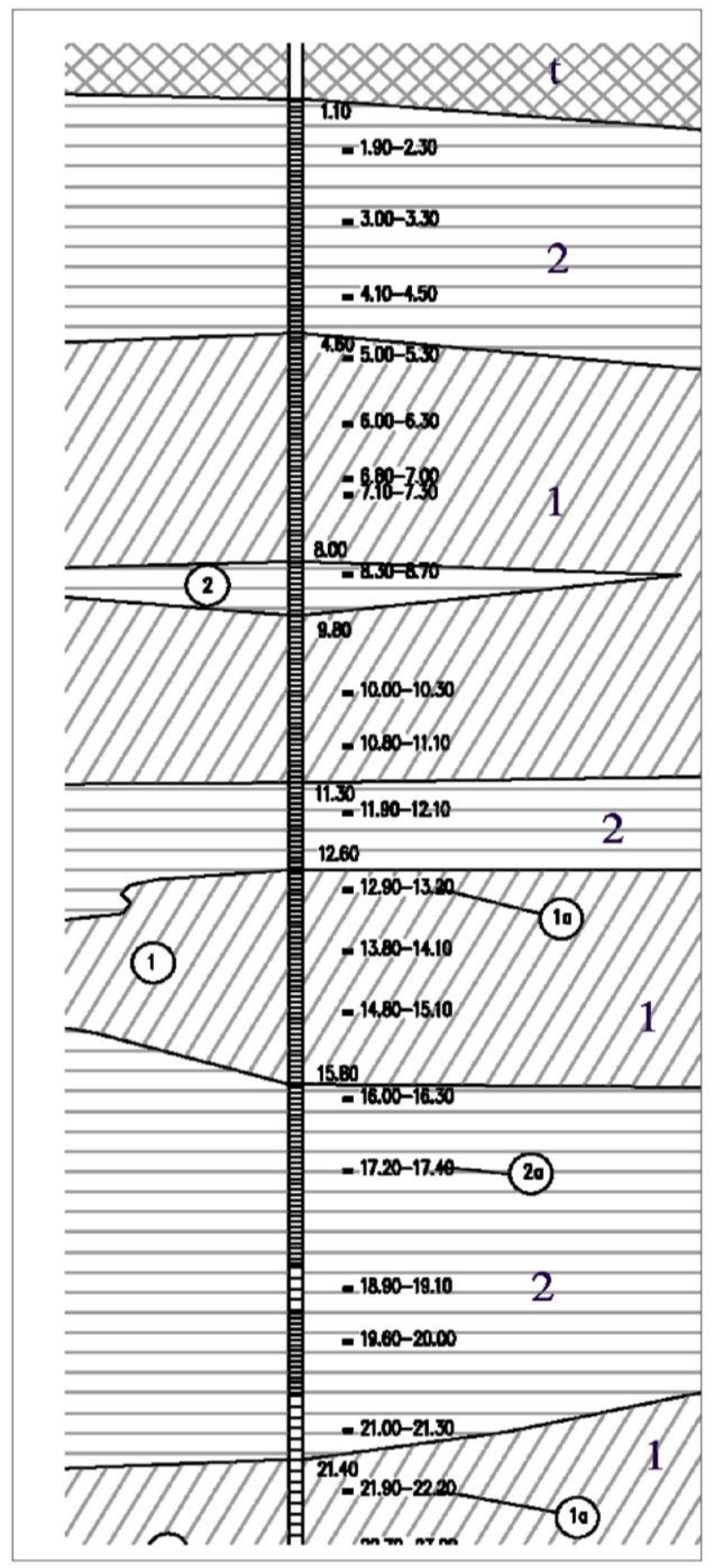

Fig. 3. Geological section of the well. 


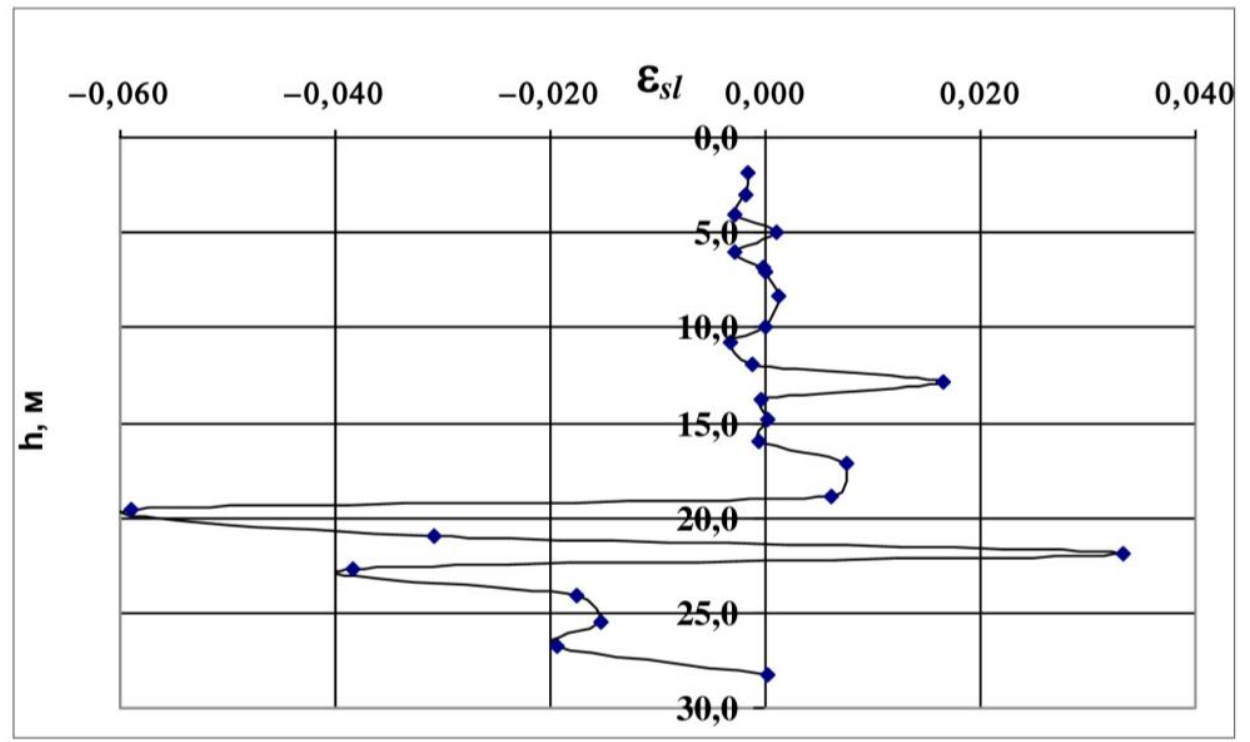

Fig. 4. Graph of subsidence of soils taken from various depth: 1) the average value of the relative subsidence, u.f. - 0.0122; the thickness of the subsidence layer, $\mathrm{m}-0.8$; subsidence, $\mathrm{cm}-0.973 ; 2$ ) the average value of the relative subsidence, u.f. - 0.0178 ; the thickness of the subsidence layer, $\mathrm{m}-0.7$; subsidence, $\mathrm{cm}-1,244$; the total subsidence is 2.217 . Subsidence type - Type I.

\section{Conclusion}

Thus, based on the field work carried out on the facility and laboratory studies, the features of engineering and geological conditions of the helium plant territory were established, and a change in the physicomechanical properties of the soils of the upper part of the section and the composition of groundwater under the influence of technogenic pollution was revealed. Particularly noteworthy are the results of a study of subsidence of loess soils in the upper part of the section, which showed that soils lying on a site deeper than $6.0 \mathrm{~m}$ have subsidence only in isolated cases. The chaotic "subsidence" of monoliths taken from a depth of 13.0-20.0 m and more meters established by compression tests cannot be explained by natural causes. This can be explained only by technogenic pollution of the territory (first of all, by the irreversible effect of leaks of chemical reagents on soils). Steeping them as a result of natural causes is unlikely, given the hydrogeological conditions of the site and the poorly permeable section (clay and heavy loam) of soils that overlap the aquifer. At the same time, it is noteworthy that soils have subsidence only in separate insignificant intervals of the section, while soils located in the immediate vicinity of them do not have this ability. A possible reason for this phenomenon is the peculiarities of the soils themselves, which showed subsidence, and is associated with the peculiarities of their microstructure, the presence of salts, and any other features that require additional studies.

Also, there is no certain pattern in the distribution of swellable soils (from weakly to strongly swellable) over the depth of the section and the area of the site, which probably depends on the nature and level of pollution and the degree of remoteness from the foci of pollution. There is a decrease in shear resistance during steeping: the angle of internal friction decreases, the adhesion also decreases (Table 2). 
The obtained information is of great practical importance for predicting changes in the characteristics of the water-soil system during technogenic pollution at oil and gas facilities. The role of each proposed pollutant agent at such facilities in changing the properties of loess soils in area and depth is not the same and will be determined by the intensity of the effect of the polluting substance (strong, weak, medium), exposure time (constant, periodic, episodic). At the same time, the type of structures that are potential polluters of the territories should also be taken into account, since their influence on changing environmental conditions can be areal, linear and pointlike [7]. The revealed patterns can ultimately be used for scientific and practical purposes in solving issues of changing the bearing capacity of soils in similar conditions.

Given the significant relevance of the considered problem, it is necessary to conduct a detailed study of the effect of technogenic pollution on loess soils at oil and gas facilities in order to assess their possible changes. In this regard, the detailed analysis of studies on the strength and deformation properties of loess subsidence soils in different regions when steeping with solutions of different chemical composition and the established patterns of their change based on the results of our own laboratory and field studies described in the work of A. Levchenko deserve attention [27]. It is also necessary to study changes in the properties of loess soils at the oil and gas facilities associated with the intensification of microbiological activity $[28,29,30]$. We consider it expedient to make additions aimed at studying this problem in regulatory documents in accordance with the proposed recommendations and existing scientific developments [31, 27, 32, 33, 34].

\section{References}

1. I.V. Dudler, E.A., Vorontsov, S.P. Lyarsky, Actual problems of the humanities and natural sciences, No. 8-2, 194-200 (2015)

2. I.V. Dudler, N.M. Khayme, International conference EngepPro-2011, 6-8.09.2011, 239-240, Moscow (2011)

3. V.D. Lomtadze, Dictionary of engineering geology, N. G. Chochia, A. I. Korotkov (eds.), Publishing House of SPb GGI named after G.V. Plekhanov, 360 (1999)

4. G.A. Golodkovskaya, S.D. Voronkevich, et al., Problems of rational use of the geological environment, 103-116, Nauka, Moscow (1988)

5. R.E. Dashko, I.Yu. Lange, Scientific Reports on Resource Issues, 1, 346-349, Freiberg (2014)

6. G. Patric, J.F. Barker, et al., Pace Report, No. 86-1, phase II, 185-193 (1986)

7. V.T. Trofimov, V.V. Baulin, et al., Problems of rational use of the geological environment, 37-61, Nauka, Moscow (1988)

8. R.A. Abdullin, Protection against corrosion and environmental protection, No. 10, 1015 (1995)

9. R.N.L. Andrews, Environmental impact assessment: theory and practice, 8597, Unwin Hyman, 85-97, London (1990)

10. A.L. Vinnikov, The study of the integrated environmental impact of the waste landfill of refineries. Doctoral dissertation in engineering, 22, Volgograd (2003)

11. A. Ya. Gaev, D.A. Albakasov, et al., Vestnik of Orenburg State University, No. 6-2 (56), 94-101 (2006)

12. A.S. Goryagina, A.V. Danilova, Materials of the All-Russian Scientific and Methodological Conference (with international participation). Collection: University complex as a regional center of education, science and culture, 608-615 (2015) 
13. K. V. Myachina, Geoecological consequences of oil and gas production in the Orenburg Urals. Doctoral dissertation in geographical sciences, 19, Institute for Water and Environmental Problems of the Siberian Branch of the Russian Academy of Sciences, Barnaul (2007)

14. T.V. Olenitsa, Ecological and geological situation. State geological map of the Russian Federation, scale 1: 1,000,000 (third generation). Series Ural. Sheet M-40 (Orenburg) with flap M-41. Explanatory letter. St. Petersburg, 320-327 (2013)

15. A.M. Pushchaev, V.A. Efremov, V.N. Zayonts, State geological map of the Russian Federation on a scale of 1: 200 000. Series Middle Volga. Sheet M-40-I (Perevolotsky). Explanatory letter. St. Petersburg (2000)

16. Report on engineering surveys "Technical re-equipment of the Helium Plant of I, II, III phases". "Neftegazgeodeziya" LLC. St. Petersburg (2006)

17. E.S. Kuvshinov, I.E. Kleimenova, A.A. Donetskova, Oilfield engineering, No. 9, 66-68 (2007)

18. Engineering Geology of the USSR in 8 volumes, 1, 528, Publishing house of the Moscow State University, Moscow (1978)

19. T.D. Sergeeva, T.A. Kuznetsova, Materials of the third conference of survey organizations, 58-60, PNIIS OJSC, Moscow (2008)

20. Vecherniy Orenburg, No. 36 (2004) http://www.vecherniyorenburg.ru/cat558/show9733/

21. A.Ya. Gaev, I.V. Kudelina, T.V. Leontyeva, Ecology of Urban Territories, No. 3, 2836 (2013)

22. E.B. Savilova, A. Ya. Gaev, et al., Vestnik of Perm University, 3 (16), 80-87 (2012)

23. E.B. Savilova, N.P. Galyanina, et al., Materials of the annual session of the Scientific Council of the Russian Academy of Sciences on problems of geoecology, engineering geology and hydrogeology, 426-231, Moscow (2013)

24. V.I. Korobkin, A.V. Korobkin, Materials of the first all-Russian conference of survey organizations "Prospects for the development of engineering surveys in construction in the Russian Federation", 49-53, PNIIS OJSC, Moscow (2006)

25. N.G. Korvet, M.B. Zavodchikova, N.I. Steklyannikova, Collection of articles on the materials of the XLIX international scientific and practical conference, No. 12 (47), SibAK Publishing House, Novosibirsk (2016)

26. V.T. Trofimov, V.V. Baulin, I.S. Zektser, et al., Problems of rational use of the geological environment, 37-61, Nauka, Moscow (1988)

27. A.P. Levchenko, Report on research work. Features of the interaction of bases and foundations on loess subsidence soils under conditions of saturation with technological and domestic wastewater. Moscow Region State University; Innovative Scientific and Technical Center "Engineer", No. 1, 558 (2010)

28. I.N. Bolotina, A.V. Minervin, M.E. Usupaev, Engineering Geology, No. 5 (1983)

29. R.E. Dashko, I.Yu. Lange, International Journal of Geotechnical Engineering, No. 5/6, 50-63, Moscow (2013)

30. A.K. Larionov, T.N. Nizheradze, M.A. Lazdovskaya, Vestnik of LSU, ser. 7, No. 28, issue 4, 35-41 (1987)

31. R.E. Dashko, I. Yu. Lange, Notes of the Mining Institute, No. 211, 16-21 (2015)

32. V.A. Mironenko, N.S. Petrov, Geoecology, No. 1, 5-47 (1995)

33. T.G. Ryashchenko, Regional soil science (Eastern Siberia), 287, Institute of Earth's Crust of SB RAS, Irkutsk (2010) 
34. N.M. Khansivarova, A.N. Kuderkin, V.I. Korobkin, Materials of the XII All-Russian conference of survey organizations. Prospects for the development of engineering surveys in construction in the Russian Federation, 58-66 (2016) 